\title{
Weight loss and reductions in body mass index, abdominal-girth and -depth after a 12 week dietary intervention of soya beans (edamame)
}

\author{
S. M. Findlay, J. McKenzie, E. Al-Dujaili and H. I. M. Davidson \\ Dietetics Nutrition and Biological Sciences, Queen Margaret University, Edinburgh EH21 6UU, UK
}

Weight loss strategies utilising dietary protein have been extensively studied. Some success has been evident with highprotein-low-carbohydrate diets; however these by nature include high fat meat or dairy produce and as such contain large amounts of saturated fat and cholesterol and may not sustain a quality diet. Literature suggests that protein supresses hunger beyond what would be estimated from its energy content ${ }^{(1)}$. Substituting even modest amounts of protein for carbohydrate is thought to reduce abdominal obesity ${ }^{(2)}$ and could therefore be of benefit in replacing some carbohydrates with sources of protein which are low in saturated fat.

The aim of this study was to examine the efficacy in maintaining energy balance or weight loss in a free-living population while incorporating frozen soya beans (edamame) into the diet and to assess changes in body weight and composition.

Overweight and obese women (BMI $>25 \mathrm{~kg} / \mathrm{m}^{2}$ ) were recruited from East Lothian, Scotland and randomised to test or control groups. Both groups were given healthy lifestyle advice while the test group were also given soya beans and asked to consume 80 g/day. Participants were reviewed at baseline, 4, 8 and 12 weeks when body weight (Wt), BMI, waist circumference (WC) and sagittal abdominal depth (SAD) were measured.

Median (M) and interquartile range (IQR) values are presented below. Sixteen women median age 49 (IQR 18) years completed the intervention programme. Significant reductions in BMI, body weight, WC and SAD were evident $p<0 \cdot 05$.

\begin{tabular}{|c|c|c|c|c|c|c|c|c|c|c|c|c|}
\hline & \multicolumn{6}{|c|}{ Control $(n=8)$} & \multicolumn{6}{|c|}{ Soya bean $(n=8)$} \\
\hline & \multicolumn{2}{|c|}{ Baseline } & \multicolumn{2}{|c|}{ Week 8} & \multicolumn{2}{|c|}{ Week 12} & \multicolumn{2}{|c|}{ Baseline } & \multicolumn{2}{|c|}{ Week 8} & \multicolumn{2}{|c|}{ Week 12} \\
\hline & $\mathrm{M}$ & IQR & $\mathrm{M}$ & IQR & $\mathrm{M}$ & IQR & $\mathrm{M}$ & IQR & $\mathrm{M}$ & IQR & $\mathrm{M}$ & IQR \\
\hline BMI & $28 \cdot 1$ & $6 \cdot 3$ & $27 \cdot 2$ & $6 \cdot 8$ & $27 \cdot 5$ & $5 \cdot 9$ & $30 \cdot 4$ & $4 \cdot 5$ & $29 \cdot 5^{\mathrm{b}}$ & $4 \cdot 0$ & $29 \cdot 2^{\mathrm{ab}}$ & $4 \cdot 6$ \\
\hline Wt (kg) & $76 \cdot 7$ & 11 & $76 \cdot 5$ & $15 \cdot 2$ & $76 \cdot 1$ & $13 \cdot 2$ & $84 \cdot 1$ & $7 \cdot 8$ & $81 \cdot 9^{\mathrm{a}}$ & $7 \cdot 7 b$ & $81 \cdot 1^{\mathrm{ab}}$ & $8 \cdot 1$ \\
\hline $\mathrm{WC}(\mathrm{cm})$ & $85 \cdot 6$ & $9 \cdot 4$ & $84 \cdot 0$ & $10 \cdot 3$ & $83.9^{b}$ & $7 \cdot 8$ & $88 \cdot 2$ & $14 \cdot 7$ & $87 \cdot 9^{\mathrm{ab}}$ & $13 \cdot 4$ & $85 \cdot 3^{\mathrm{abc}}$ & $14 \cdot 1$ \\
\hline $\mathrm{SAD}(\mathrm{cm})$ & $24 \cdot 2$ & $2 \cdot 8$ & $23 \cdot 8$ & $2 \cdot 2$ & 23.9 & $2 \cdot 2$ & $27 \cdot 3$ & $3 \cdot 6$ & $26 \cdot 7^{\mathrm{ab}}$ & 3.7 & $26 \cdot 1^{\mathrm{ab}}$ & $3 \cdot 5$ \\
\hline
\end{tabular}

${ }^{\mathrm{a}}$ Significantly different from baseline $p<0.05{ }^{\mathrm{b}}$ Significantly different from week $4 p<0.05^{\mathrm{c}}$ Significantly different from week $8 p<0.05$. No significant difference was seen between baseline and week 4. Friedman's ANOVA with post hoc Wilcoxon Signed-ranks test.

These interim results indicate that incorporating soya beans into the diet, as part of a healthy lifestyle, may assist in weight loss and improvements in abdominal obesity in an overweight/obese female population. However, it remains to be elucidated whether these results can be generalised to the population as a whole and whether improvements in other lifestyle behaviours such as activity contribute to the weight loss seen. Further investigation into controlling energy intake in association with elevated protein from soya beans may provide an effective weight-loss strategy.

1. Astrup A. (2005) The satiating power of protein-a key to obesity prevention? Am J Clin Nutr 07 82(1), 1-2.

2. Merchant AT, Anand SS, Vuksan V, et al. (2005) Protein intake is inversely associated with abdominal obesity in a multi-ethnic population. $J$ Nutr 05 135(5), 1196-1201. 